\title{
A NECROESPACIALIDADE NOS CEMITÉRIOS SÃO JOÃO BATISTA E PARQUE DA PAZ EM FORTALEZA - CEARÁ
}

\author{
Gleilson Angelo da Silva \\ Universidade Federal do Ceará (UFC) \\ Pós-Graduação em Geografia, Fortaleza, CE, Brasil \\ angelosilva002@gmail.com
}

\begin{abstract}
RESUMO
O artigo apresenta a necroespacialidade em dois cemitérios de Fortaleza: São João Batista e Parque da Paz (construídos em épocas diferentes mostram o pensamento da sociedade sobre a morte). O objetivo foi entender como os espaços cemiteriais podem ser considerados como reflexos da produção do próprio espaço urbano. De levantamento bibliográfico à pesquisa de campo o intuito foi evidenciar no real e identificar elementos que embasassem o propósito de reconhecê-los como um dos equipamentos mais importantes cidade. Por meio da organização dos túmulos, foi possível identificar elementos característicos que são resultados deste reflexo a partir do século XIX, no qual a cidade passou por grandes transformações que afetaram, sobretudo, estes espaços. Fazendo um paralelo com os processos políticos, econômicos e sociais, aborda não somente o aspecto concreto dos campos santos como a simbologia encontrada nos túmulos, jazigos e mausoléus podendo ser compreendidas como formas simbólicas espaciais.
\end{abstract}

Palavras-chave: Espaço. Cemitério. Necroespacialidade. Formas Simbólicas Espaciais. Espaço Urbano.

\section{NECRO-SPACE IN THE CEMETERIES SÃO JOÃO BATISTA AND PARQUE DA PAZ IN FORTALEZA - CEARÁ}

\begin{abstract}
The article presents necro-spatiality in two cemeteries in Fortaleza: São João Batista and Parque da Paz (built at different times show the thinking of society about death). The objective was to understand how cemetery spaces can be considered as reflections of the production of the urban space itself. From bibliographic survey to field research, the aim was to highlight the real and identify elements that support the purpose of recognizing them as one of the most important equipment in the city. Through the organization of the tombs, it was possible to identify characteristic elements that are the result of this reflection from the 19 th century, in which the city underwent major transformations that affected, above all, these spaces. Paralleling political, economic and social processes, it addresses not only the concrete aspect of the holy fields but also the symbolism found in tombs, tombs and mausoleums, which can be understood as spatial symbolic forms.
\end{abstract}

Keywords: Space. Cemetery. Necro-spaciality. Spatial Symbolic Forms. Urban space.

\section{PARA ALÉM DA NECROESPACIALIDADE}

A necroespacialidade pode ser compreendida como a espacialização dos túmulos ${ }^{1}$, mausoléus e jazigos nos cemitérios e os espaços cemiteriais são o resultado de todo um processo que envolve a produção da cidade e das relações sociais que sofreram alterações e transformações que interferiram nos hábitos e costumes da sociedade. Em Fortaleza, estas necroespacialidades podem ser observadas nos cemitérios em questão, uma vez que, foram construídos em épocas diferentes sob determinados contextos políticos, econômicos, culturais, sociais, dentre outros. O próprio desenvolvimento de Fortaleza é a base para o entendimento da transformação dos espaços cemiteriais e como os acontecimentos internos e externos modificaram os chamados campos santos.

Desta forma, os cemitérios de São João Batista e Parque da Paz figuram como apenas um exemplo do processo de urbanização que a capital passou por mais de um século até se apresentar da forma como se pode observar, mas também em constante processo de transformação. A partir de uma

1 Local onde uma ou mais pessoas são enterradas no cemitério que pode se tornar sinônimo de jazigo e sepultura. Disponível em: http://www.dicio.com.br/tumulo/. Acesso em: 15 de novembro de 2019.

$\begin{array}{lllll}\text { Caminhos de Geografia } & \text { Uberlândia-MG } & \text { v. 22, n. } 81 & \text { jun./2021 } & \text { p. 15-29 }\end{array}$


perspectiva da geografia histórica, compreende-se os campos santos como uma espécie de museu a céu aberto, sobretudo os chamados tradicionais. São neles que podemos identificar, com maior clareza, todos os processos nele imbricados. Mas, como surgiu este pensamento sobre a morte e a construção de um cemitério?

Para apreender o sentido de cemitério, é necessário compreender um pouco da história de Fortaleza, como ela foi inserida no contexto nacional e internacional, uma vez que, a ideia de cemitério foi trazida da Europa para cá. Desta forma, compreende-se a cidade a partir dos campos santos, uma vez que, uma é decorrente da outra (não necessariamente nesta ordem), investiga-se o surgimento de um espaço destinado exclusivamente para os enterros tal como o pensamento empregado na organização, dos tipos e simbologias decorrentes de todo o processo que envolve escalas e fenômenos decorrentes dos processos pelos quais Fortaleza passou.

A importância que os cemitérios possuem para a cidade muitas vezes é obscurecida pela imagem que a sociedade construiu sobre a morte e o morrer envolta de sentimentos e lembranças que, muitas vezes, são dolorosas e são concretizadas a partir de monumentos erguidos para os falecidos. Assim, este espaço da cidade é renegado, mas ao mesmo tempo, reverenciado no dia de finados quando ele se torna o protagonista na cidade. Para além de entender somente o que é necroespacialidade, devese compreender o que é a morte e o morrer para a sociedade e justificar este lugar escolhido para os mortos.

\section{DA IDADE MÉDIA PARA A CONTEMPORÂNEA: A MORTE E OS CAMPOS SANTOS...}

De acordo com Ariès (2000), a morte e seus rituais podem ser observados desde a Antiguidade no qual muitos autores descrevem como acontecia e, posteriormente, resultaram em muitos dos rituais que praticamos até hoje.

Desde a Idade Antiga muitos foram os rituais fúnebres até a sua instalação definitiva dentro da sociedade. Quando passou a ser incorporado ao urbano tornou-se um símbolo religioso e ao mesmo tempo profano, pois haviam dois tipos de falecidos: os cristãos e os pagãos. A Idade Média foi um divisor de águas na espacialização dos túmulos, sobretudo, dentro das igrejas no qual se iniciou o pensamento tradicional levado aos cemitérios extra-muros. (SILVA, 2015, p. 100).

Para não alongar, os rituais fúnebres e os lugares escolhidos variaram ao longo da Idade Média até se destinar um específico na cidade (ou fora dela, nos arredores, ao redor das igrejas, enfim) e também os tipos de sepultamentos.

Ad Sanctos, carneiros, catacumbas, ossários, dentre outros foram utilizados para os sepultamentos até a instalação definitiva de um campo santo, partindo da Europa e difundido para o resto do mundo (ARIÈS, 2000, p. 65).

No Brasil, esta ideia se propaga e os costumes dos enterros nos cemitérios tornam-se habituais, embora houvessem inúmeras pessoas que rejeitassem esta prática. A partir destas perspectivas, introduzimos os estudos acerca do processo de construção dos espaços cemiteriais em Fortaleza e como estas transformações ainda podem ser encontradas na configuração espacial dos cemitérios da capital. Desta forma, compreende-se a cidade a partir dos campos santos, uma vez que, a transformação no espaço urbano, causa-lhe profundas mudanças nos seus mais diversos âmbitos, sendo um deles o viés de cunho cultural tendo relação direta com a Identidade e a Memória.

\section{RÉQUIEM A SÃO CASEMIRO}

O primeiro cemitério da cidade, apesar de não mais existir, fora implantado a partir de um processo que se iniciou na França no início do século XIX e se alastrou por várias cidades até chegar à capital alencarina, não com a mesma intensidade, mas que refletiu todo um discurso médico higienista numa época em que Fortaleza passava por profundas transformações: era o São Casemiro. Localizado fora do perímetro urbano da cidade, até então, foi uma das várias construções como um símbolo de modernidade, uma vez que, datam da mesma época: o Liceu do Ceará (1845); a Santa Casa de Misericórdia (1861); o farol do Mucuripe e o Seminário da Prainha (1864); o Passeio Público, na praça dos Mártires, a primeira biblioteca e a Cadeia Pública (1870); a implantação da Rede de Viação Cearense, melhoramentos do velho porto e a construção da Ponte Metálica (1897) (FARIAS, 2012). 
Antes deste campo santo, os enterros eram realizados na antiga igreja de São José (demolida em 1938 onde hoje se encontra a Catedral Metropolitana) e na igreja do Rosário, sendo esta a mais antiga da capital, construída ainda no século XVIII. A sua localização, como já foi mencionado, ficava distante do centro da cidade e onde hoje se localiza a praça Castro Carreira, mais conhecida como praça da Estação, por nela estar instalada a antiga estação João Felipe e hoje faz parte do chamado Centro histórico de Fortaleza (figura 1).

Figura 1 - Localização do cemitério São Casemiro e dos principais equipamentos de Fortaleza em 1859.

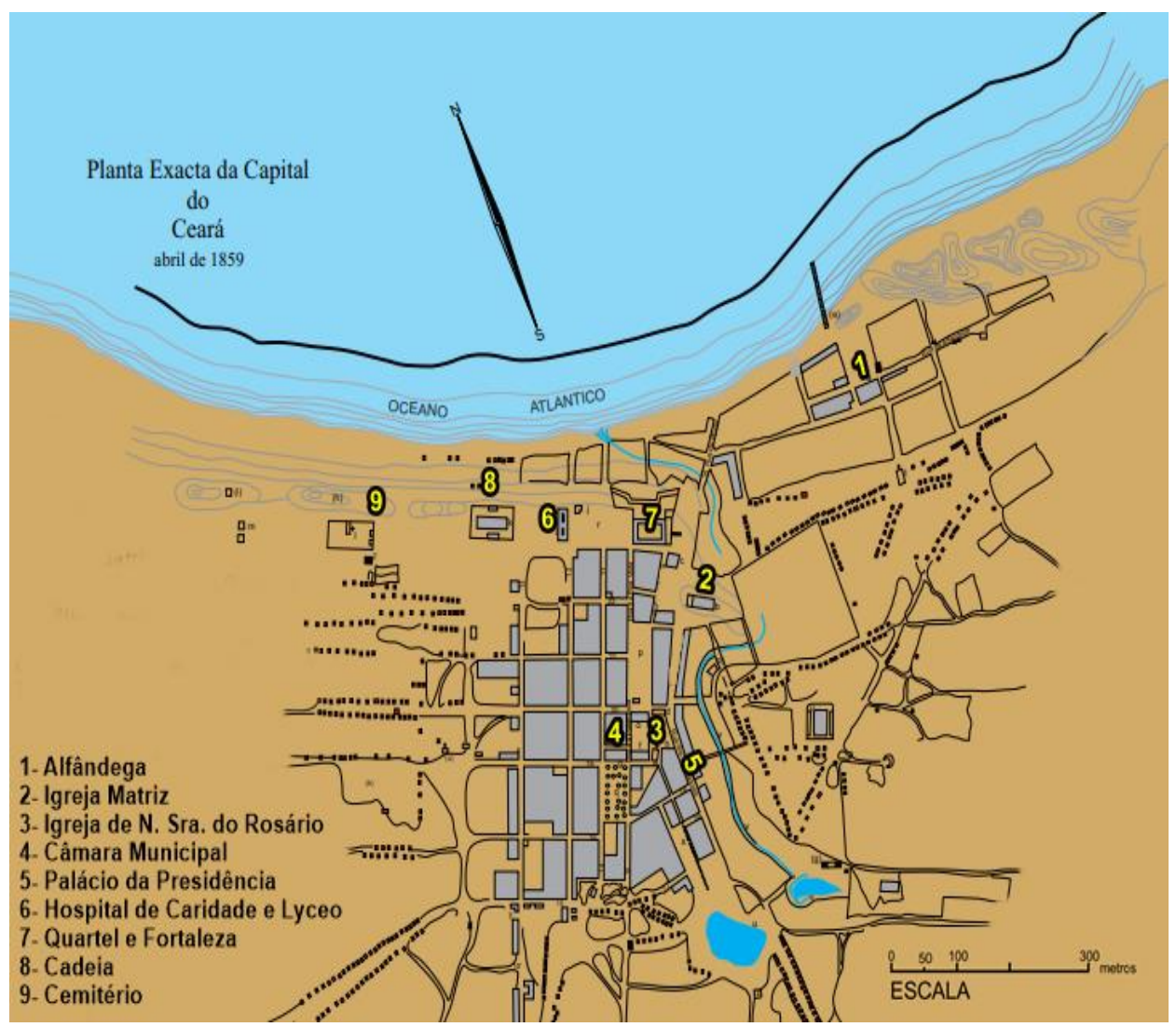

Fonte - Planta Exacta da capital do Ceará, elaborada por Adolfo Herbster. Elaborado por: Andrade (2016). Adaptado por Silva (2019).

Sua elevação à vila e seu status, posterior de cidade, não condiziam com a realidade, uma vez que, Fortaleza sempre teve muitos problemas estruturais, administrativos e todos os elementos que uma capital deveria comportar. Jucá Neto (2012) nos explica que, dentro de uma lógica espacial no século XVIII até o século seguinte, Fortaleza não era considerada uma vila importante por se tratar apenas de um ponto de passagem entre Oeste e Leste. Quando esta se torna a capital da província, inicia um processo de transformação espacial para receber os principais equipamentos fundamentais para a função administrativa.

O século XIX traz inúmeros componentes que fizeram com que Fortaleza se tornasse, até o final deste, a principal vila. Tanto no campo econômico quanto no político, combinados a eventos externos e internos permitiram o destaque exponencial da capital dos quais podemos citar a produção do algodão que culminou na construção da Estrada de Ferro Fortaleza-Baturité e, consequentemente, a construção de vários equipamentos que facilitassem no transporte, armazenagem e exportação do produto (COSTA, 2005). Dentre as várias mudanças na capital alencarina, destacamos a de cunho higienista que tinha relação direta com os hábitos de higiene e costumes que foram erradicados por médicos e demais profissionais da saúde frente às grandes epidemias que assolavam a Europa e chegavam ao Brasil, sobretudo às vilas (depois cidades) no Nordeste, juntamente com os retirantes da seca que chegavam à Fortaleza. Montesuma (2006, p. 6) demonstra a relação entre as secas, epidemias e os processos oriundos na Europa que transformou a capital. 
Em Fortaleza, entre 1850 e 1860, surge verdadeira compulsão saneadora, segundo o modelo francês, em sintonia com o momento vivido pela cidade, no auge da exportação algodoeira, consolidando-se como principal centro político, social, comercial e financeiro do estado [...]. As grandes epidemias, de alta letalidade, ocorridas no período - varíola, 1824/5; febre amarela, 1851/3; cólera, 1862; e varíola, 1877/8 - receberam como resposta pública a consolidação de instituições de isolamento, a de Jacarecanga, a da Lagoa Funda, os lazaretos provisórios e a construção da Santa Casa de Misericórdia de Fortaleza, inaugurada em 1861. O Ceará ingressa numa prática contemporânea de saúde, exercida por enfermeiros qualificados e médicos formados no Brasil, em Salvador ou no Rio de Janeiro. O primeiro desta geração foi o Dr. José Lourenço, diplomado no Rio de Janeiro, que criou a Inspetoria de Saúde do Estado e foi seu primeiro responsável.

Para além destas medidas outras também foram implementadas como a construção de campos de concentração e um cemitério fora do perímetro urbano para afastar os chamados miasmas causadores de doenças. Costa (2014) explicita acerca dos ideais higienistas europeus e como eles chegaram ao Ceará através dos médicos mencionados por Montesuma (2006) anteriormente, utilizando-se de vários autores para compreender como os discursos influenciaram na construção dos cemitérios e explica o motivo da sua localização. A condenação dos enterros nas igrejas foram um dos principais atributos para efetivar uma espécie de reforma higienista. Silva $(2015$, p. 70$)$ explica que

Depois de muitos relatórios e diversas manifestações por parte dos médicos e intelectuais que defendiam o fim dos enterros nas igrejas e, aliado às ideias vigentes da França e concretizadas na Bahia através da Cemiterada, o primeiro cemitério de Fortaleza é construído.

A Câmara ficou encarregada de elencar profissionais que escolhessem um lugar adequado para a instalação do cemitério de São Casemiro (cujo nome homenageia o então Presidente da província Casimiro José de Morais Sarmento) no qual fizeram parte do processo médicos formados em Salvador, no Rio de Janeiro ou fora do Brasil como: Liberato de Castro Carreira, José Lourenço Castro e Silva e Marcos José Theophilo (OLIVEIRA, 2007). A partir da lei n. 319 de 1ํ de agosto de 1844 a construção do devido cemitério é iniciada, sendo finalizada em 1849, tendo a Santa Casa de Misericórdia propriedade sobre o mesmo (BEZERRA DE MENEZES, 1992).

A necroespacialidade neste cemitério estava na restrição dos enterros destinados aos católicos, ou seja, seguindo preceitos que foram estabelecidos ainda na Idade Média para aqueles que contribuíssem e dedicassem toda sua vida em prol da igreja, enquanto que, para os que não se encaixavam no perfil, como os Protestantes, judeus, por exemplo, não tinham direito ao enterro no mesmo local que os católicos. A solução foi construir ao lado do cemitério, um outro, especificamente, para os que não fossem católicos ficando a cargo da casa de importação e exportação Singlehurst \& Cia., de Henrich Brocklehurst (FARIAS, 2012) a responsabilidade de manter este campo santo.

Nogueira (1981) salienta que os enterros ocorreram até 1865 devido a problemas como: o soterramento pelas areias do morro do Croatá que se localizava ao lado do cemitério numa área aonde os ventos que chegavam do litoral espalhava o odor para a cidade e os enterros de vítimas da epidemia de cólera tornaram-no cada vez mais insalubre resultando em seu abandono. No mesmo período já estava sendo debatida a construção de um novo cemitério para a capital, visto que, aquele estava insustentável cuja inauguração ocorreu somente em 1880, embora já recebesse enterros desde 1866. A demolição deste cemitério iniciou em 1877 e um processo de exumação dos corpos também foi iniciado para que fossem destinados ao novo cemitério construído para além do perímetro urbano e onde hoje se localiza em um bairro vizinho ao Centro. No seu lugar, como mencionado anteriormente, fora construído uma praça (Castro Carreira ou Estação) e a estação João Felipe cuja via férrea também já foi mencionada (Estrada de Ferro Fortaleza-Baturité).

\section{SÃO JOÃO BATISTA, A MODERNIDADE EM FORMA DE MÁRMORE}

Com a inauguração de um novo cemitério houve a necessidade de traslar os corpos do antigo, como o de Antônio Rodrigues Ferreira, o boticário Ferreira (cuja praça mais famosa da cidade recebe seu nome), dentre outros no qual aqueles que a família reivindicou ou teve grande importância fora transferido com êxito enquanto que, os que não foram reivindicados ou eram indigentes muitas vezes eram deixado para trás. 
A nova necrópole se localizava pra além dos limites da cidade e cujo dano à saúde dos fortalezenses era o mínimo ou quase nulo, uma vez que, estando a oeste fazia com que os ventos do litoral emanassem para longe os miasmas provindos dos corpos daqueles que estavam ou fossem enterrados ali. O status de necrópole foi incorporado ao campo santo de acordo com as tendências europeias que chegavam por meio da arte cemiterial com a construção de grandes mausoléus ornados de materiais provindos do outro lado do Atlântico, principalmente, Portugal (NOGUEIRA, 1981).

Os novos hábitos mudaram a visão sobre a morte, uma vez que, alguns elementos foram incorporados não somente aos rituais fúnebres como os cortejos entre a igreja de São José e o novo cemitério através da então rua das Flores (cuja denominação refere-se ao caminho entre a igreja e o cemitério), atual Castro e Silva (ADERALDO, 1993). Outra característica observada nesta época foi o aparecimento de ornamentos nos túmulos que engrandeciam e tomavam uma proporção que sintetizava o poder e prestígio daquela personalidade ou de sua família perante a sociedade. Lefèbvre (1983) afirma que as construções são o resultado das relações sociais, uma vez que, se relacionarmos o espaço dos vivos encontramos semelhanças com o espaço dos mortos quanto ao modo como os túmulos foram construídos e organizados no cemitério.

Tendo nome homônimo com o cemitério no Rio de Janeiro, possui características relevantes importantes para compreender o processo de urbanização de Fortaleza: grande parte das personalidades provindas de famílias influentes na capital está enterrada neste campo santo, simbolizada por grandes mausoléus na entrada próximo à capela demonstrando como o poder após a morte foi simbolizado através dos monumentos que ornamentam e definem o status social ao qual aquela pessoa pertenceu. A configuração espacial dos túmulos neste cemitério o caracteriza como tradicional pela paisagem que é formada a partir da junção de mausoléus e jazigos e possui relação ínfima com o espaço urbano em si a partir da segregação que é formada entre os planos que fazem parte do cemitério. Na figura 2 observamos como este espaço cemiterial está dividido no qual devemos atentar a sua configuração para compreendermos como a segregação está estabelecida. Comparado a outros tipos de cemitérios, este se apresenta de forma verticalizada que simula uma cidade sendo comumente chamada de necrópole (cidade dos mortos) trazendo muitos elementos da Idade Média e após este período.

Figura 2 - Localização do cemitério São João Batista e seus três planos.

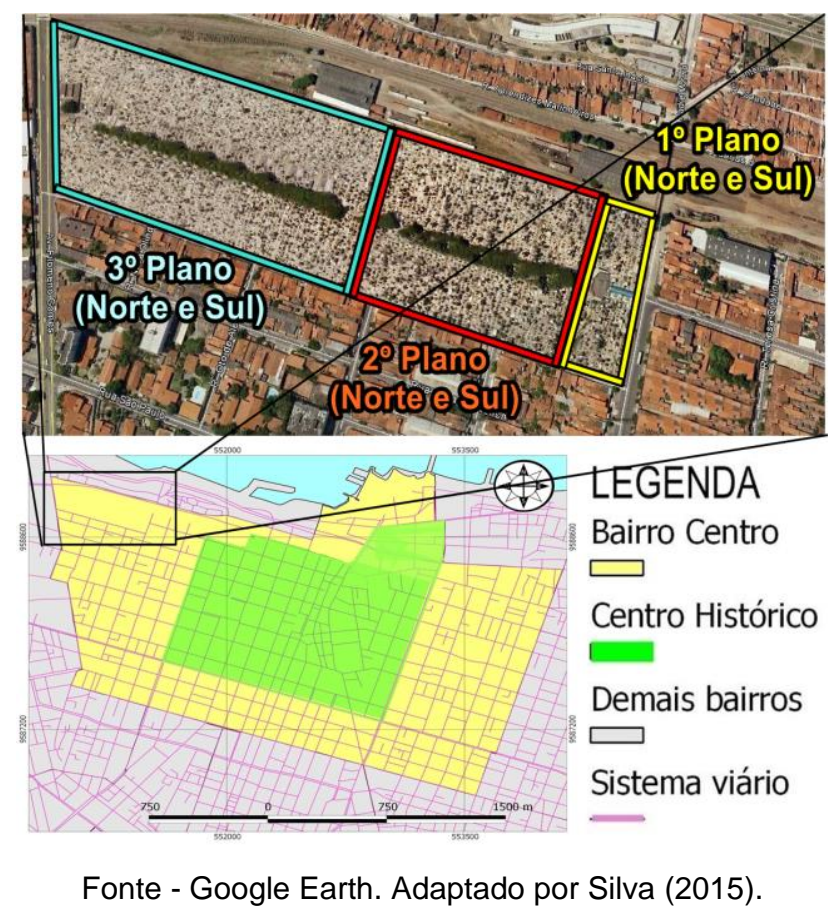

Não há um número exato de túmulos existentes e nem o total de pessoas sepultadas, uma vez que, a Santa Casa de Misericórdia (atual administradora do cemitério) não possui alguns documentos do 
final do século XIX que enumere os sepultamentos e nem identifique, mas estima-se que haja mais de quinze mil túmulos. De acordo com os funcionários, o tamanho padrão dos jazigos é de $1,20 \mathrm{~m} x$ 2,40m, mas que não é observado em boa parte dos túmulos, uma vez que, esta padronização é evidente no primeiro e uma porção do segundo. A conservação dos jazigos e mausoléus é feita a partir do recebimento da mensalidade do terreno feito pela família daqueles que ali estão enterrados, porém, o estado de conservação encontrado reflete o abandono e a degradação, pois alguns mausoléus possuem estátuas e esculturas muitas vezes furtadas, devido aos detalhes feitos de materiais como cobre, mármore, dentre outros. Apesar disso, muitos familiares mantêm os ornamentos sempre bem cuidados fazendo com que o conjunto de mausoléus torne-se um museu a céu aberto que reflete um pouco da história de Fortaleza. As figuras 3, 4 e 5 demonstram como os três planos se espacializam por meio dos mausoléus e como são destoantes, sobretudo em relação ao terceiro plano.

Figura 3 - Primeiro plano.

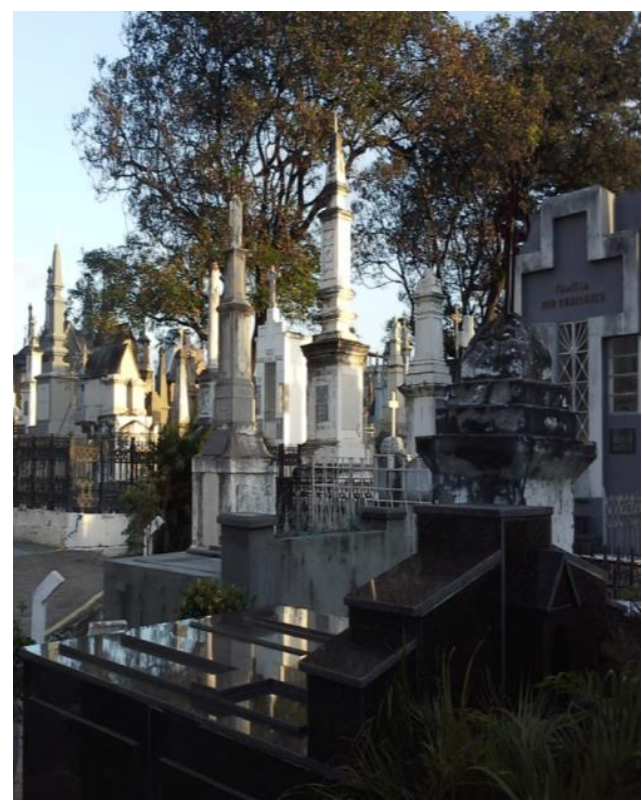

Fonte - Silva (2015).
Figura 4 - Segundo plano.

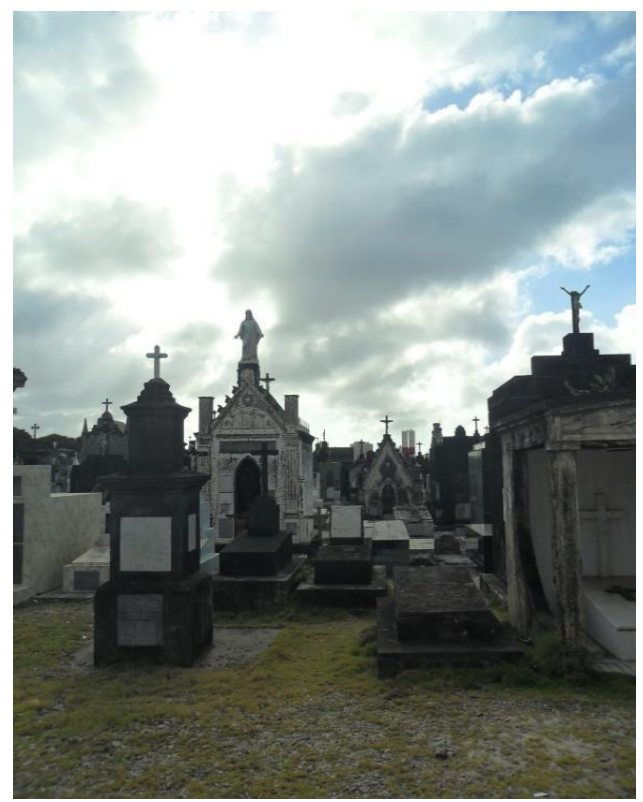

Fonte - Silva (2015).

Figura 5 - Terceiro plano.

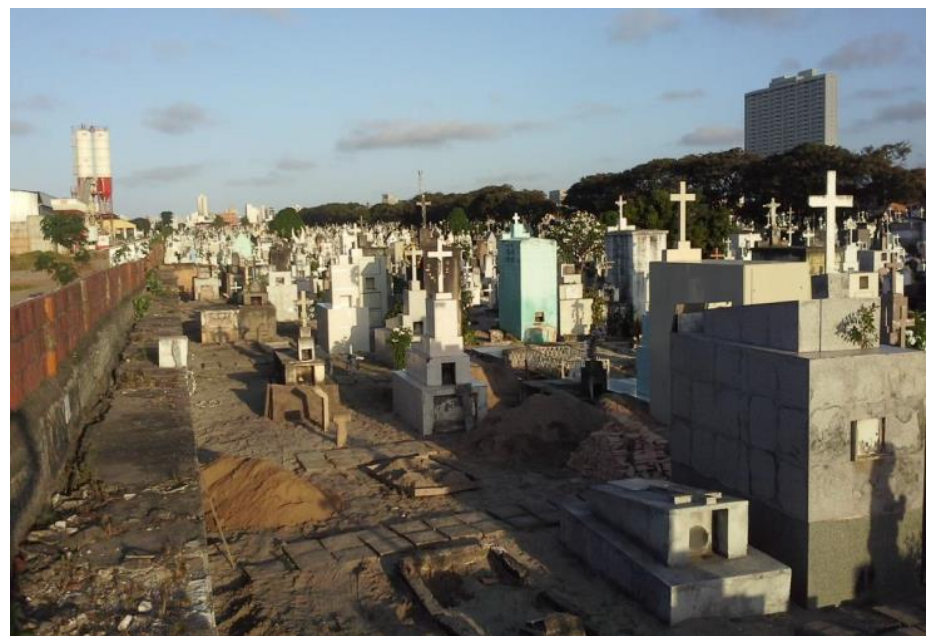

Fonte - Silva (2015).

Visualmente, é nítida a diferença entre os planos pelo porte dos mausoléus e túmulos, mas também pela organização, uma vez que, a paisagem que é formada reflete uma segregação entre classes. Isto é justificado por dois motivos: o primeiro, de acordo com Batista (2002, p. 63) é que "a necrópole 
já era vista não só como lugar de memória, mas também como espaço onde o túmulo era elevado à condição de arte", ou seja, somente aqueles que possuíam um alto poder aquisitivo adquiriam peças advindas da Europa para ornamentar o túmulo ou mausoléu da família. O segundo foi observado uma mesma lógica espacial de sepultamentos herdadas da Idade Média com os Ad Sanctos (dentro das igrejas), ou seja, quanto mais próximo da capela mais perto do céu e, sucessivamente, da salvação.

Silva (2015) caracteriza os três planos desta forma:

Ao percorrer as ruas do Primeiro Plano conhecemos um pouco da história de Fortaleza e do Ceará, pois ali estão as personalidades mais conhecidas da política, medicina, arquitetura, dentre outros (...) e também observa-se o padrão tumular nas ruas do Primeiro Plano com muitas referências ao estilo em voga na época e que seguiam os padrões europeus, tanto no que se refere ao material como também das impressões esculpidas (p. 81)

No Segundo Plano, ainda é possível ver um padrão tumular semelhante ao primeiro através do seguimento da época, datados a partir da primeira metade do século $X X$ (...). Esse é considerado como o auge do romantismo, no qual a maioria das famílias tradicionais empregavam toda a sua riqueza na construção dos famosos mausoléus e seus respectivos símbolos (p.83-84).

O Terceiro Plano é o maior e mais popular do cemitério, no qual ainda se encontram mausoléus de famílias de outras nacionalidades, jazigos de associações como a dos Merceeiros (figura 6) e a dos motoristas do Ceará (figura 7). Porém, o maior contingente é de túmulos simples até o final do cemitério no qual há uma série de gavetas nos muros denominados de blocos que vão de $A$ à $Z$ (figura 8 ). Estes delimitam o final do cemitério que denota o total e completo abandono por parte dos familiares que ali possuem entes queridos. São, na sua maioria, degradados, alguns já violados e totalmente desgastados pelo tempo. As partes laterais que também serviam como gavetões estão abertos e com alguns ossos à vista, resultado de vandalismo, saques e depredações o que torna essa parte do cemitério a menos visível e mais deteriorada (figura 9) (p. 87).

Esta ligação entre os símbolos (sejam sagrados ou profanos) com o espaço onde estão inseridos, pode estar relacionado com o que Rosendhal (2004) denomina de mundo imaginalis que permeia o mundo real com o espiritual através de rituais e símbolos que, neste caso, podem ser identificados como as esculturas e símbolos presentes nos túmulos e mausoléus.

As figuras 6, 7, 8 e 9 apresentam a variedade de ritos e símbolos presentes, sobretudo, no Terceiro Plano. Ritos no que se refere ao modo de enterrar (muitas vezes em blocos, como sob a forma de associações até uma simples demarcação de jazigo) e símbolos no que se refere ao pensamento sobre a morte a partir do formato dos túmulos e jazigos.

Figura 6 - Túmulo no Terceiro Plano.

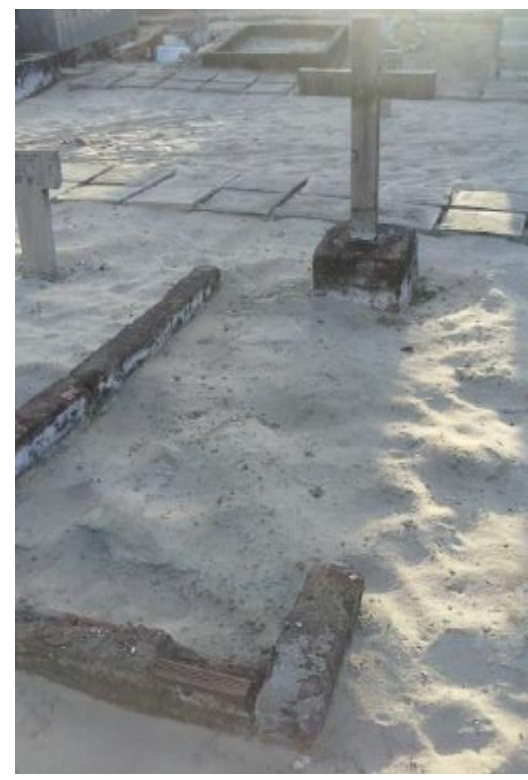

Fonte - Silva (2015).
Figura 7 - Associação de Merceeiros.

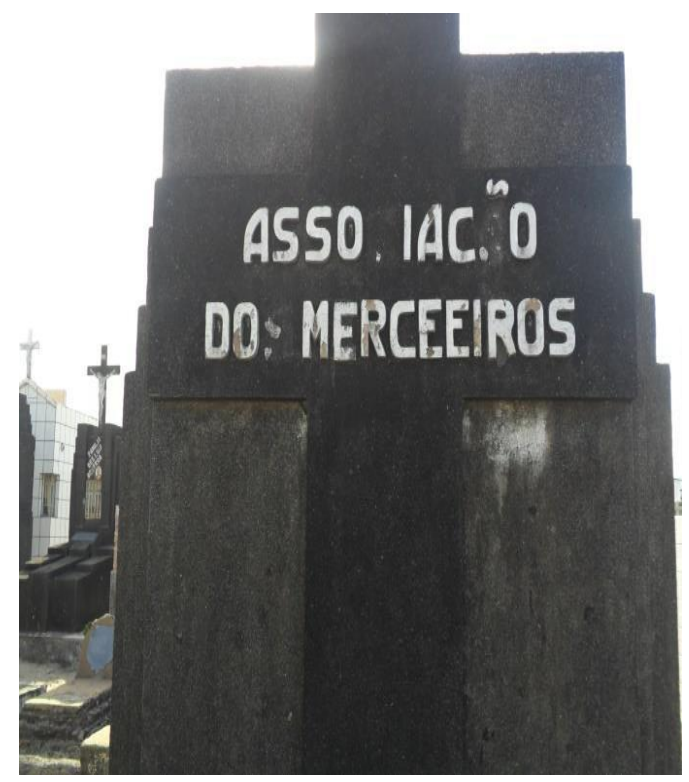

Fonte - Silva (2015). 
Figura 8 - Bloco Y.

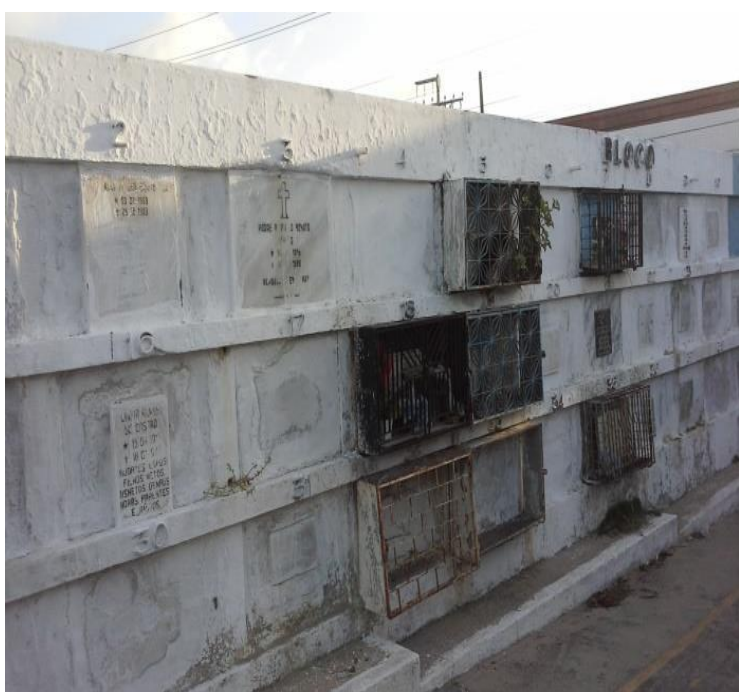

Fonte - Silva (2015)
Figura 9 - Gavetões nas laterais do cemitério.

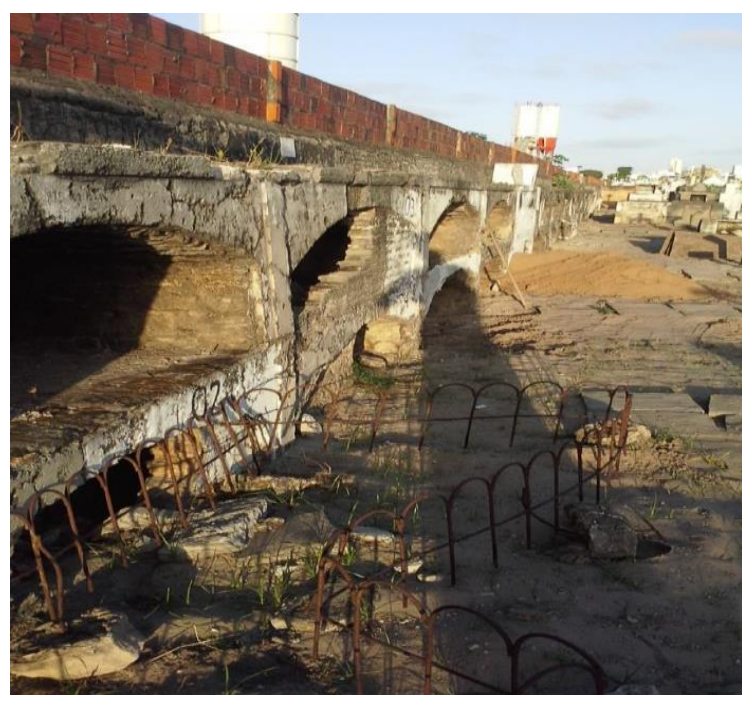

Fonte - Silva (2015).

A contradição no cemitério tradicional é encontrada comparando-se os dois primeiros planos com o terceiro, de modo que, as condições não são as mesmas e o estado de conservação é lastimável (embora, neste caso, é um problema que ocorre em todos os planos). As associações e ligas estão presentes no São João Batista, tendo como exemplo a figura 7 (Associação dos Merceeiros) assim como outras também possuem seu espaço no cemitério configurando-lhes uma forma coletiva de enterro de pessoas que trabalharam num certo ramo.

Compreende-se uma parte da espacialização dos túmulos, mausoléus e jazigos, de modo que, embora houvesse uma nítida mudança na lógica de pensamento acerca da morte (dos enterros dentro das igrejas para a construção de um local específico para este fim) o simbolismo que a necroespacialidade exerce é bastante presente, sendo o reflexo da mudança da própria sociedade, sobretudo no que diz respeito à segregação socioespacial. Preteicelle $(2003$, p. 32) aponta que este processo é o resultado de

Uma herança histórica dos efeitos dos movimentos da economia e da sociedade, no longo prazo, centralizada tanto nas estruturas materiais do espaço construído como nas formas sociais de valorização simbólica e de apropriação.

Esta relação entre o material e o imaterial está presente no conjunto de túmulos presentes no cemitério, sobretudo no primeiro plano, uma vez que, mescla elementos como o poder econômico e símbolos que envolvem religião, política, estados de espírito e retratam como a morte é interpretada pelas pessoas, muitas vezes, utilizando-a como ferramenta de luto e discurso. Assim, podemos relacionar a necroespacialidade tanto às relações sociais que refletem a hierarquia das classes a partir dos planos existentes no cemitério e que estão diretamente ligadas à própria produção do espaço urbano quanto à segregação sócioespacial (centralidade e periferia) e também com as relações sociais por meio do trabalho (MOREIRA, 1982).

Do ponto de vista simbólico, o cemitério São João Batista pode ser relacionado diretamente à memória, aos símbolos e significados que, não somente, os adornos possuem, mas os materiais utilizados na construção dos mausoléus e demais túmulos. Batista (2002, p. 63) traduz o poder que a importação de determinados materiais possuem para simbolizar o poder que a família do (a) falecido (a) possuía: "Ao comprar um jazigo das oficinas de cantarias² portuguesas, importava-se não somente o artefato pétreo, mas todo o conjunto de códigos". Desta forma, de anjos a estátuas de diversos tamanhos podem ser encontrados nos mausoléus, sobretudo, do primeiro plano (enfatizando o poder econômico das famílias) tal como materiais como: cobre, mármore, prata, ouro, dentre outros e que, infelizmente, alguns destes são furtados devido ao seu valor no mercado, como mencionado

2 Arte ou ofício de entalhar na pedra e que fora apropriado pelas marmorarias especializadas para a decoração funerária e a produção de estatuárias tornando-se famosas as de origem portuguesa e importadas por famílias no Brasil no século XIX (MOTTA, 2010). 
anteriormente. Corrêa (2002) aponta que os símbolos são resultados das relações sociais expressos não só no espaço como também marcam o tempo em que foram produzidos e, neste caso, representa uma fase da história de Fortaleza em que a Europa, sobretudo a França ditava moda, mas a influência portuguesa nos cemitérios brasileiros se fez mais presente.

Muitos dos símbolos estão diretamente relacionados com as circunstâncias em que os mortos estavam inseridos, seja no aspecto político, religioso, enfim, representa o que foi em vida e, a partir dos elementos empregados em seus mausoléus, também representaria após sua morte. Corrêa (2007) aponta que, quando as formas dialogam (simbolicamente) com o espaço em que estão inseridas, tornam-se Formas Simbólicas Espaciais (de uma forma simplificada sendo que estas relações são bem complexas), ou seja, o conjunto de estatuária e demais elementos funerários que simbolizam a morte podem ser considerados Formas Simbólicas Espaciais, pois dialogam com o espaço em que estão inseridos, caracterizando-se como canal de comunicação entre os responsáveis por sua construção e o lugar onde estão localizados.

Figura 10 - O anjo.

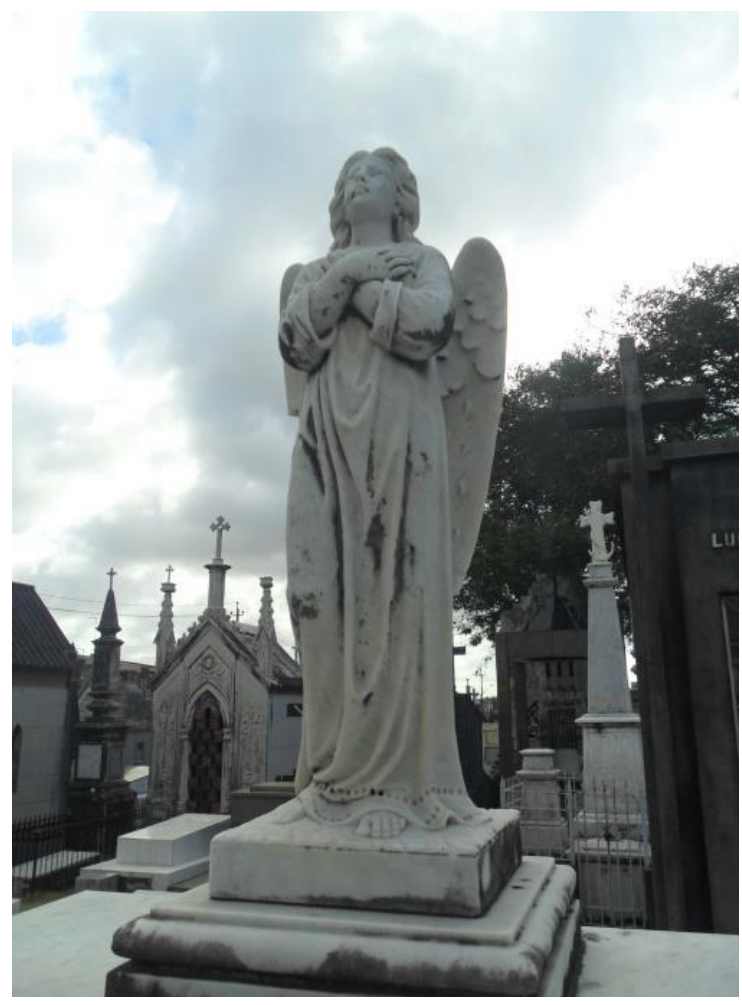

Fonte - Silva (2015).
Figura 11 - O vaso.

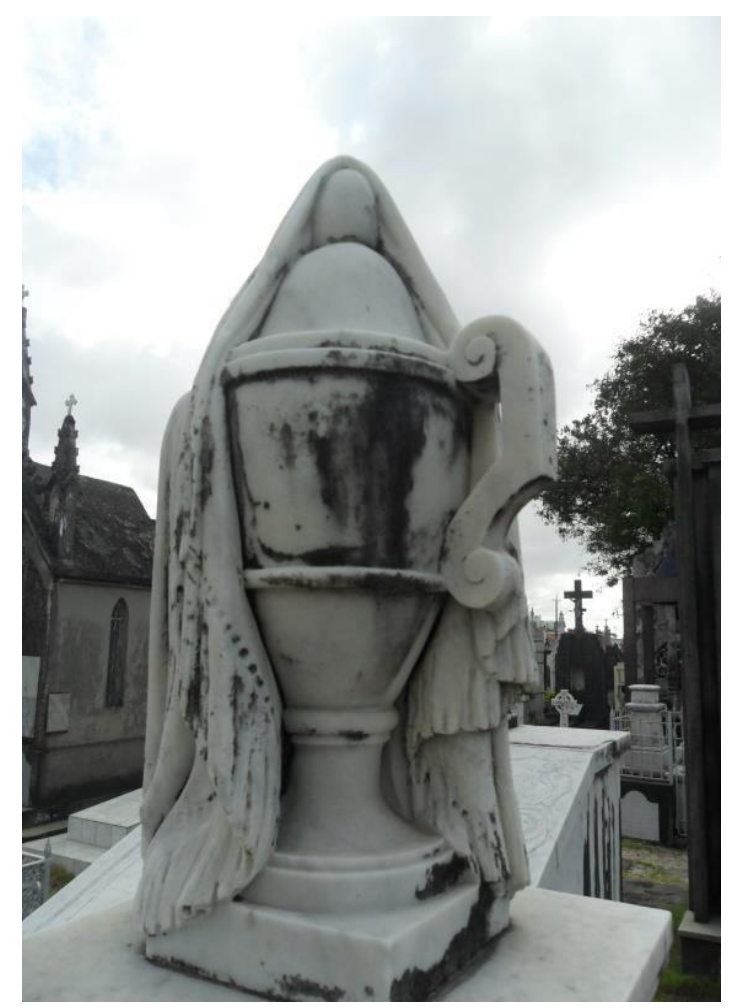

Fonte - Silva (2015).

Estas formas são explicitadas por Silva (2015) como parte conjunto de elementos que simbolizam a morte que envolve: tochas invertidas, colunas, obeliscos, coroa de flores, correntes, diversos tipos de cruzes e demais peças sacras. As figuras 10 e 11 representam dois dos elementos para além dos já citados, uma vez que, o anjo (dependendo da forma como foi esculpida) representa um sentimento perante o falecido simbolizando, muitas vezes, a pureza, a justiça e a virtude. O vaso representa o corpo sem a alma, de modo que, se encontra vazio. Estes dois exemplos demonstram como a morte é simbolizada por formas que adquirem um significado e são passíveis de mudanças no qual os sentimentos perante a morte estão associados a outros elementos.

Ainda de acordo com Silva (2015) o elemento predominante no cemitério é a cruz em suas mais variadas formas e tamanhos tornando-se o elemento mais simbólico da morte. A sua presença é maior quando os túmulos ficam mais simples e quanto mais se adentra no cemitério, uma vez que, observa-se a ausência de grandes mausoléus e a simplicidade das lápides se resume a uma cruz com o nome, data de nascimento e de falecimento como uma forma de identificação e que se encontra, em sua grande maioria, no terceiro plano (o maior do cemitério). Poucos são os túmulos 
que se destacam dentre a quantidade de cruzes existentes e quanto mais ao fundo do campo santo se chega mais precários são os túmulos não significando que a sua importância seja menor do que os demais planos, uma vez que, a morte possui um significado diferente sendo representada das mais diversas formas.

\section{PARQUE DA PAZ: UMA PAISAGEM CEMITERIAL}

O cemitério Parque da Paz está localizado no bairro Passaré, distante do Centro onde está situado o cemitério São João Batista, possui várias peculiaridades tornando-o importante para a história não somente dos cemitérios fortalezenses como para a própria capital, uma vez que, o fator espaçotempo exprime as características que o distingue dos demais. Inaugurado em 18 de maio de 1973 é o primeiro cemitério-parque da capital alencarina e também do Norte e Nordeste ${ }^{3}$ do país, sendo inspirado no mesmo modelo que o cemitério Père-Lachaise em Paris (inaugurado em 1804). Porém, ao contrário do cemitério francês aquele não foi construído em uma floresta, mas todos os elementos naturais presentes foram plantados no terreno junto com os setores.

Reiterando as peculiaridades, uma delas está a de que a sua localização é bem mais distante do que o citado anteriormente evidenciando a expansão da cidade, a partir da década de 1930 e intensificado em meados dos anos 1950, tornando-se centro de uma metrópole ainda na década de 1970 (FARIAS, 2012).

O Decreto Municipal no 59 de 12 de maio de 1970, sancionado pelo então prefeito José Walter, estipula que

Art. 1ํ - O estabelecimento de cemitérios particulares, no caso em que a sociedade filantrópica assumir os encargos de sua construção e administração, se dará mediante permissão do Prefeito Municipal, por prazo não superior a noventa e nove anos.

Art. $2^{\circ}$ - Os cemitérios-parques se caracterizam essencialmente por áreas livres, gramadas e arborizadas, não sendo permitidos monumentos particulares, muretas, grades ou quaisquer outros elementos construídos nas áreas destinadas às sepulturas.

Art. $3^{\circ}$ - São Condições essenciais para a aprovação de projetos de cemitériosparques, quando requeridos por entidades filantrópicas nos têrmos da Lei:

a) Situar-se em local previamente aprovado pelas autoridades municipais, fora das zonas residenciais e comercial, devendo 0 terreno apresentar condições topográficas favoráveis e ter uma superfície não inferior a 10 (dez) hectares nem superior a 25 (vinte e cinco) hectares;

b) Prever uma faixa verde de isolamento, com largura mínima de 10 (dez) metros, com arborização e vegetação adequadas e alambrado de fechamento circundando o cemitério, cuja altura será fixada no projeto de urbanização;

c) Prever vias pavimentadas destinadas ao tráfego de veículos, que deverão ser projetados de tal forma que favoreçam o acesso aos setores de sepultamento, bem como vias secundárias para pedestres;

Art. $7^{\circ}$ - Ressalvadas as concessões legalmente concedidas à Santa Casa de Misericórdia de Fortaleza, relativamente a / serviços fúnebres, a presente Lei entra em vigor na data de sua publicação, revogadas as disposições em contrário (FORTALEZA, 1970).

Não havia decretos ou artigos claros para a construção e limitação de cemitérios até então, demonstrando, por exemplo, uma nova visão sobre a função de cemitério para um viés ambiental, de modo que, o São João Batista foi construído sem um planejamento do ponto de vista ambiental (até porque não se tinha este tipo de discurso em sua época).

Outra particularidade é a diferença na administração: enquanto que o Parque da Paz está a cargo da EBRAL - Empresa Brasileira de Lançamentos ${ }^{4}$, uma empresa particular o São João Batista está a cargo da Santa Casa de Misericórdia, tornando-se o primeiro cemitério administrado por uma empresa particular e o único ainda dentro do perímetro urbano, pois todos os outros cemitérios-

3 Disponível em: http://www.cemiterioparquedapaz.com.br/sobre-nos. Acesso em: 16 de novembro de 2019.

${ }^{4}$ Disponível em: http://www.cemiterioparquedapaz.com.br/sobre-nos. Acesso em: 16 de novembro de 2019.

Caminhos de Geografia $\quad$ Uberlândia-MG $\quad$ v. 22, n. $81 \quad$ jun./2021 $\quad$ p. 15-29 Página 24


parque que foram criados posteriormente estão situados fora do perímetro. De acordo com Drumond (2004), esta nova lógica cemiterial modificava o significado da morte no âmbito visual se comparado aos cemitérios tradicionais como o São João Batista, uma vez que, os grandes mausoléus e as esculturas deixavam o ambiente pesado. A implantação de um parque, de acordo com Silva (2015) traz uma nova concepção sobre o cemitério, pois a sua configuração permite uma naturalização a partir da paisagem natural: árvores, bancos, grama e, principalmente, a padronização nos jazigos. Se nos cemitérios tradicionais a opulência construía grandes mausoléus, neste tipo de cemitério as lápides são padronizadas e não permitem uma modificação drástica.

Figura 12 - Setorização do cemitério Parque da Paz.

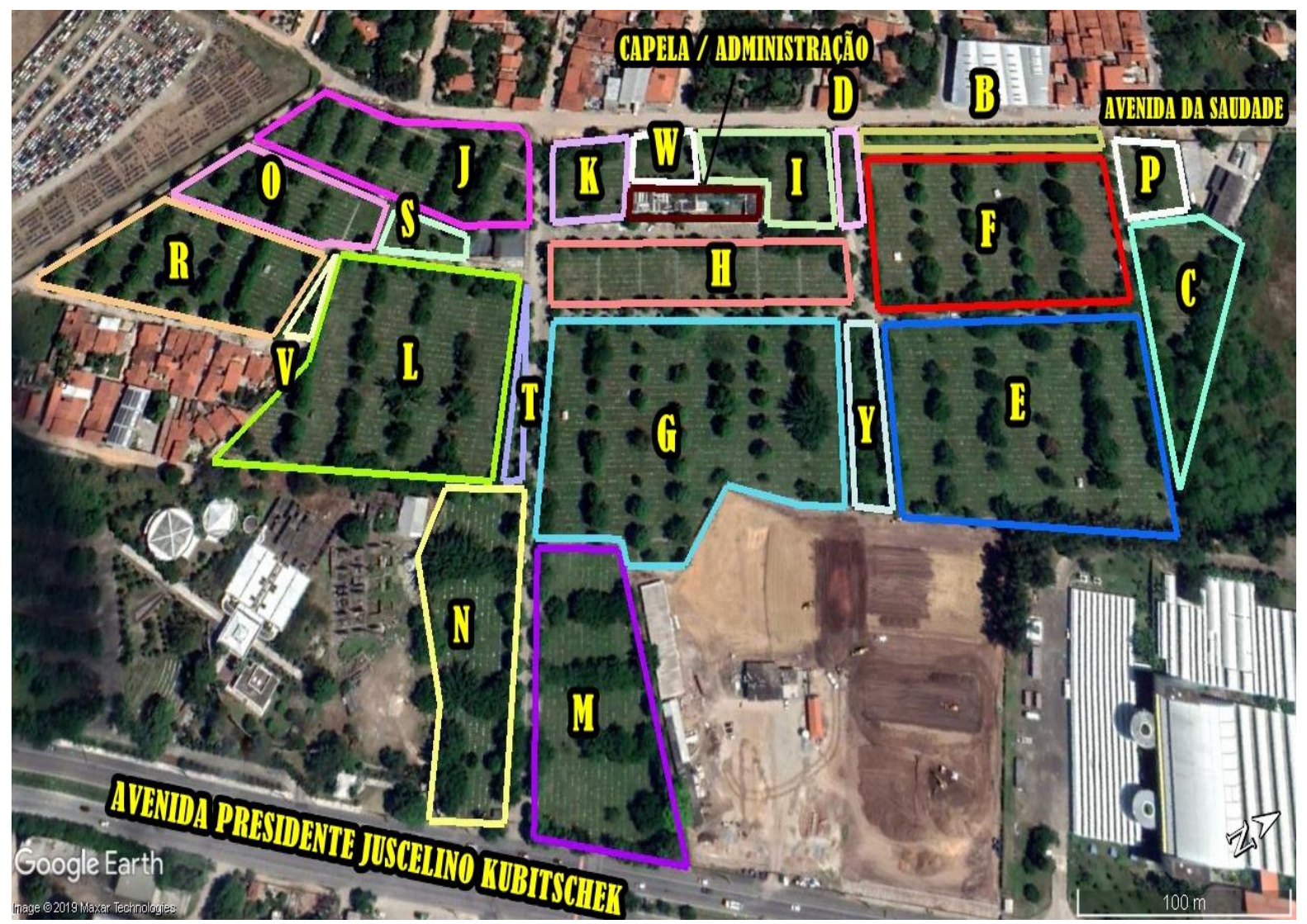

Fonte - Google Earth. Elaborado e adaptado por Silva (2019).

Outra particularidade bastante pertinente está na sua configuração espacial, ou seja, no modo como ele está dividido. Numa área superior a $10 \mathrm{mil} \mathrm{m}^{2}$ e mais de vinte e três mil jazigos com três compartimentos ${ }^{5}$, localizado entre as avenidas Presidente Juscelino Kubitschek e da Saudade, com uma via de acesso que atravessa o cemitério, possui uma configuração diferente do São João Batista (como pode ser observado na figura 8) não mais em planos, mas em quadras que se dividem em setores e estes, sucessivamente, em jazigos. Esta divisão está presente nos jazigos, pois eles são localizados obedecendo esta configuração, sendo três grandes faixas de preços com denominações de árvores (Ipê, Jatobá e Juazeiro) divididos em vinte e um setores: Juazeiro $(H, I, K, W)$, Jatobá (B, $D, F)$ e Ipê (demais).

A junção de poucos setores em uma grande quadra refere-se ao preço, ou seja, quanto mais próximo da capela (onde estão situados os setores da faixa de preços Juazeiro) são os mais elevados cujos jazigos para sepultamento imediato ultrapassam o valor de $R \$ 25.000,00$, enquanto que nos setores pertencentes à faixa do Jatobá são de $R \$ 20.000,00$ e Ipê, $R \$ 15.000,00^{6}$. Desta forma, a

${ }^{5}$ Disponível em: http://www.cemiterioparquedapaz.com.br/servicos. Acesso em: 16 de dezembro de 2019.

${ }^{6}$ Disponível em: https://cemiterioparquedapaz.com.br/jazigos-de-uso-imediato/. Acesso em: 16 de dezembro de 2019. 
organização por faixa de preços é condizente com a configuração espacial, embora a lógica espacial não siga um padrão, uma vez que, ao entrar no cemitério os primeiros setores são o $\mathrm{M}$ e o $\mathrm{N}$ não havendo uma organização tanto no tamanho quanto na própria localização. Porém, o mais instigante e semelhante ao cemitério tradicional é a elevação do preço em uma determinada área do parque. Do mesmo modo que os mausoléus do cemitério São João Batista refletem o poder aquisitivo daqueles que estão sepultados tal como de suas famílias, no Parque da Paz isto fica evidente ao compararmos faixa de preços com a localização dos setores: ambos ficam próximos à capela.

Figura 13 - Paisagem cemiterial.

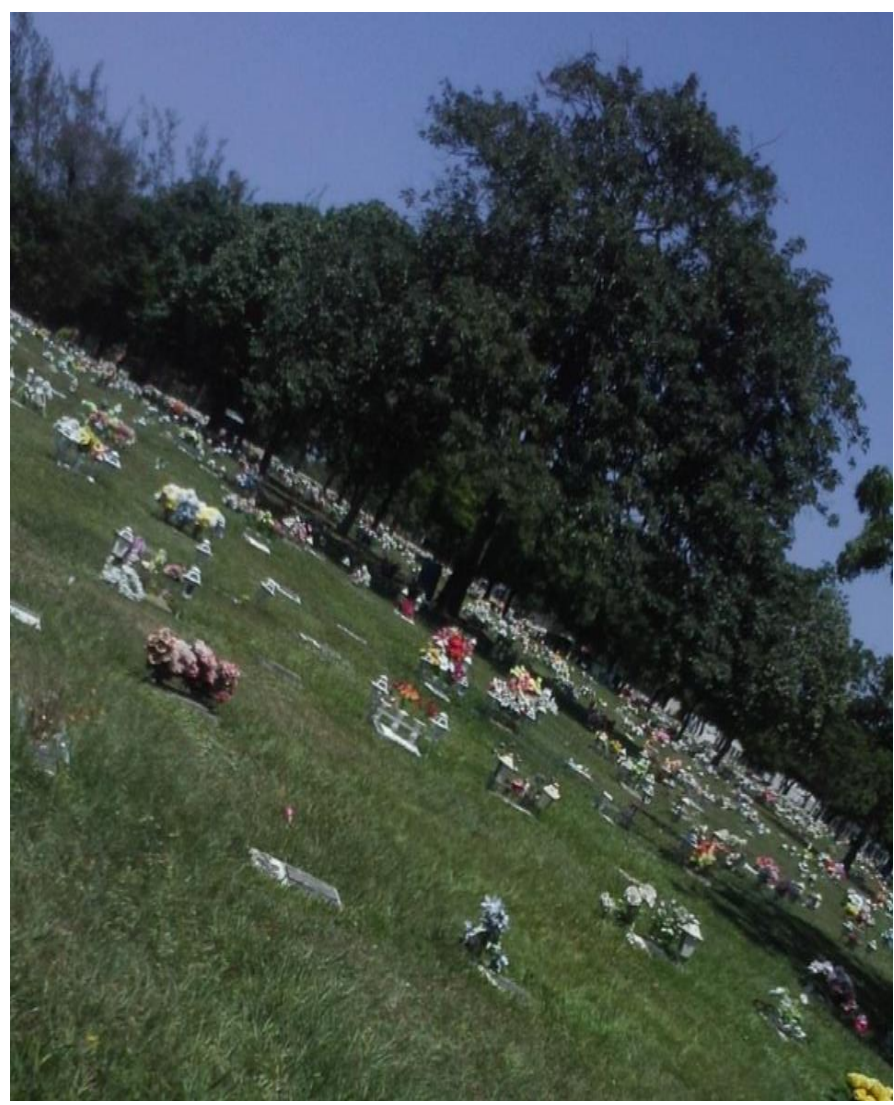

Fonte - Silva (2015).

A figura 13 apresenta a visão que se tem sobre uma parte do cemitério, mas, em um primeiro momento ele não se configura como um cemitério propriamente dito se comparado ao cemitério tradicional pela ausência de grandes mausoléus e túmulos adornados tornando o ambiente menos pesado e trazendo elementos que simbolizam a "naturalização" da morte por meio de árvores, bancos e a grama fazendo jus à denominação de cemitério-parque, outrora, também muito comum na Europa medieval mesmo de forma diferente.

Os dois objetos de estudos demonstram semelhanças e divergências do ponto de vista metodológico, pois os dados e informações muitas vezes são condizentes e, às vezes, divergentes. Para um levantamento bibliográfico para ambos foi necessário compreender como a sociedade traduzia a morte e qual a origem (mais moderna possível) dos ritos fúnebres como se conhece hoje. Sabe-se que, desde o Egito Antigo, a energia dos vivos jamais poderia afetar a energia dos mortos, de modo que, uma cidade para os mortos foi construída do outro lado do rio (que simboliza a vida) (ARIĖS, 2000). Desta forma, a morte foi renegada da vida social por muitos anos, sendo reintroduzida somente na Idade Média de onde partiu este estudo.

Como referência de pesquisa de uma geografia histórica, Abreu (2011, p. 571) explana a importância que o passado tem para a Geografia: "o passado tem muito a informar aos geógrafos" e sobre os fatos que aconteceram refletem e conseguem fazer uma leitura sobre os processos e fenômenos atuais. Desta forma, compreender os cemitérios é fazer uma leitura da própria cidade a partir da sua

$\begin{array}{lllll}\text { Caminhos de Geografia } \quad \text { Uberlândia-MG } & \text { v. 22, n. } 81 \quad \text { jun./2021 } & \text { p. 15-29 Página } 26\end{array}$


construção e dos processos que fizeram com que ela chegasse na forma como se encontra na atualidade.

Para além do elenco de palavras-chave como: espaço, formas simbólicas espaciais, cemitério, morte, houve também a necessidade de se compreender o urbano e seus fenômenos tal como uma metodologia para conciliar fatos com conversas informais e informações verídicas ou não estabelecendo uma linha de raciocínio para que todos estes fatores auxiliassem numa linguagem clara e objetiva acerca dos fenômenos.

Fortaleza passou por muitos processos em pouco tempo, dentro de um século, assistiu a população crescer sete vezes mais do que quando tornou-se capital mesmo sem ter um aporte físico necessário. O trabalho de campo em busca de imagens e demais elementos pertinentes revela a necessidade de aliar teoria e prática na Geografia e de como as leituras feitas em gabinete podem ser aplicadas no real/concreto. Assim, houve uma complementaridade entre leitura e campo com conversas informais, pois não havia a necessidade de aplicar questionários, entrevistas porque o fenômeno em si explicaria.

Poderia ter sido feito de diversas formas e com diversas abordagens, mas não supriria os questionamentos que a pesquisa se propôs a responder e o descobrimento de tantas informações que somente o trabalho em campo proporcionou enriqueceu a pesquisa e permitiu inúmero outros questionamentos que poderiam ser trabalhados e esmiuçados, mas não para este momento.

Desta forma, os dois cemitérios foram escolhidos por serem os pioneiros em suas épocas, embora o São Casemiro não exista mais, o São João Batista tornou-se representativo no final do século XIX com a construção de imponentes mausoléus de grandes personalidades que nomeiam os mais diversos logradouros da cidade: Senador Pompeu, Major Facundo, Boticário Ferreira, Frei Tito, João Dummar, Virgílio Távora, Barão de Aracati, Barão de Studart, dentre tantos outros. O Parque da Paz, por trazer uma ideia diferente do São João Batista, trouxe um olhar diferente sobre a morte e o morrer, mas não dos rituais fúnebres. Porém, numa outra lógica (a comercial) ele se especializou e fez com que outros fossem criados ao longo do tempo.

Apesar de ser o mais conhecido, o São João Batista não é o único cemitério público no estilo tradicional, existindo ainda: o de Parangaba, o de Antônio Bezerra, o de Mucuripe e o de Messejana (este sendo o mais antigo da capital, anterior ao São João Batista, pois à época este bairro não fazia parte de Fortaleza) ${ }^{7}$. Ainda há o cemitério parque (público) do Bom Jardim, sendo o último campo santo público construído dentro do perímetro urbano no início dos anos 1990.

\section{PARA NÃO TERMINAR PELA HORA DA MORTE}

Observa-se que, embora os dois cemitérios sejam diferentes do ponto de vista da forma, paisagística, eles são semelhantes do ponto de vista histórico, uma vez que, obedecem a uma lógica da Idade Média em que, quanto mais próximo do altar/igreja/capela, mais próximo da salvação a pessoa estará. Silva (2015) ainda explicita que, mesmo que o cemitério Parque da Paz não permita manifestações religiosas, a lógica estabelecida entre os setores demonstra uma forte ligação com o Catolicismo enfatizando o poder do divino/sagrado materializado sob a forma de capela.

A Forma e a Função são trazidas como ênfase dos processos pelos quais passaram os dois cemitérios em questão e como se apresentam hoje como resultado de todas as mudanças pelo qual passaram e ainda permanecem como marcas no espaço (SANTOS, 1985). Embora os dois possuam a mesma função (lugar de sepultamento) suas formas são diferentes e trazem sensações adversas assim como a simbologia da morte, pois, enquanto que, num cemitério tradicional a morte é tratada com pesar por meio do sofrimento e estatuárias que representam a dor, mas é rico em história, pois ali estão sepultadas personalidades que contribuíram (ou não) para o desenvolvimento da cidade de Fortaleza durante todo o século XIX e XX, no cemitério Parque da Paz cuja simbologia da morte é retratada de forma diferente a partir do nome, assim como outros cemitérios-parque como: Jardim Metropolitano, Parque da Saudade, Parque das Flores, Jardim do Éden, dentre outros, seguindo até sua estrutura (como o próprio nome refere-se: um parque ou jardim).

7 Gastos após a morte de um familiar podem chegar a $\mathrm{R} \$ 12$ mil (Jornal O Povo. Disponível em: https://www.opovo.com.br/noticias/fortaleza/2018/11/em-fortaleza-despesas-pos-obito-sao-de-pelo-menos-r-12mil.html. Acesso em: 16 de novembro de 2019.

$\begin{array}{lllll}\text { Caminhos de Geografia } \quad \text { Uberlândia-MG } & \text { v. 22, n. } 81 \quad \text { jun./2021 } & \text { p. 15-29 } & \text { Página } 27\end{array}$


A produção do espaço urbano influenciou diretamente na formação dos espaços cemiteriais, uma vez que, as mudanças pelas quais a sociedade passou, seja por intermédio dos meios de produção, na atuação de agentes produtores do espaço em diferentes escalas e na formação das próprias cidades, contribuíram para modificação do campo santo, construção dos cemitérios e readequação dos mesmos aos novos padrões. A morte foi representada de forma opulenta, a partir das grandes construções de mausoléus (reflexo das influências arquitetônicas europeias que a própria cidade importava) como status econômico tanto em vida quanto post-mortem (expressão em latim que significa depois da morte). Com a instalação dos cemitérios nos parques dentro das cidades, a simbologia da morte foi naturalizando-se aos poucos desembocando no conceito de cemitério-parque incorporando a paisagem natural ou construindo-as como forma de naturalizar o próprio cemitério no lugar onde fora instalado.

Para além dos cemitérios tradicionais e parques há os chamados cemitérios verticais que estão localizados em ambientes mais fechados e engavetados em estruturas verticais dentro de longos corredores e divido em andares, transportando o sentido de morte e cemitério para outra concepção, nada superior ou inferior aos já mencionados, mas de uma forma diferente. As abordagens feitas podem ser variadas dependendo do resultado e do tipo de investigação que se pretende ao estudar este tipo de cemitérios.

Além dos cemitérios verticais, há também os crematórios, lugares onde se incineram os corpos numa cerimônia mais fechada e/ou reservada e, se o aprofundamento e a curiosidade permitirem, os cemitérios esquecidos ou simplesmente soterrados, como os indígenas e, adentrado para o interior, os pequenos cemitérios nos quintais como vestígios de outro tipo de ritual: o velar do sertanejo, os cortejos, os cânticos e demais práticas e costumes encravados em cada gesto ou hábito.

Incorporado à cidade, o cemitério deveria ser mais explorado tanto do ponto de vista acadêmico, como turístico (a exemplo de cemitérios em São Paulo, no Rio de Janeiro, em Salvador, Buenos Aires, Paris, dentre outros) no sentido de preservá-los e valorizá-los como parte da cultura assim como os demais patrimônios da capital alencarina.

\section{REFERÊNCIAS}

ABREU, M. de A. Da evolução urbana à Geografia histórica do Rio de Janeiro: O itinerário de um geógrafo. CIDADES: Revista Científica, Presidente Prudente, v.8, n. 14. 2011.

ADERALDO, M. S. Histórias abreviadas de Fortaleza e crônicas sobre a cidade amada. Fortaleza: Edições UFC (Universidade Federal do Ceará)/Casa José de Alencar, 1993.

ANDRADE, L. A. S. de. Controle e expansão - códigos e plantas. Fortaleza 1813-1933. Dissertação (Mestrado em Arquitetura e Urbanismo) - Pelotas: UFPEL (Universidade Federal de Pelotas). 2016.

ARIÈS, P. O homem perante a morte (L'homme devant la mort). Tradução de Ana Rachaça. Portugal: Publicações Europa-América, Ltda., 2000.

BATISTA, H. S. de. Assim na morte como na vida: arte e sociedade no cemitério São João Batista (1866-1915). Fortaleza: SECULT (Secretaria de Cultura do Estado do Ceará), 2002.

BEZERRA DE MENEZES, A. Descrição da cidade de Fortaleza. Fortaleza: Edições UFC/Prefeitura de Fortaleza, 1992.

CORRÊA, R. L. O Espaço Urbano. São Paulo: Ática, 2002.

2007.

Formas Simbólicas e Espaço e algumas considerações. GEOgraphia - Ano IX - No 17 -

COSTA, M. C. L. Expansão da infraestrutura urbana e dos serviços públicos em Fortaleza (Brasil) na virada do século XIX. Anais do X Encontro de Geógrafos da América Latina. São Paulo: Universidade de São Paulo, 2005.

O discurso higienista e a ordem urbana. Fortaleza: Imprensa Universitária, 2014.

DRUMOND, Ranieri de Alcântara. Quanto custa morrer? A Comercialização da Morte em Fortaleza. Fortaleza: Edições UFC, 2004.

FARIAS, A. de. História do Ceará. $2^{a}$ reimpressão. - 6. ed. rev. e ampl. - Fortaleza: Armazém da Cultura, 2012. 
FORTALEZA. Lei ordinária no 3.830/1970. Fortaleza, CE: Câmara Municipal de Fortaleza, 1970. JUCÁ NETO, C. R. Primórdios da Urbanização no Ceará. Fortaleza: Edições UFC; Editora Banco do Nordeste do Brasil, 2012.

LEFÈBVRE, H. La presença y la ausencia. Fundo de Cultura Econômica: México, 1983.

MOREIRA, R. Repensando a Geografia. In: SANTOS, Milton (Org.). Novos rumos da Geografia brasileira. São Paulo: Hucitec, 1982.

MONTESUMA, Francisca Gomes; FÉ, Márcia Andréia Barros Moura; GOMES, Silvia Cristina Costa; FERNANDES, Teresa Cristina de Lima; SAMPAIO, José Jackson Coelho. Saúde pública no Ceará : uma sistematização histórica. Caderno Especial, Ceará, 2 (1): 6-19, 2006.

MOTTA, Antônio. Estilos mortuários e modos de sociabilidade em cemitérios Brasileiros oitocentistas. Horizontes Antropológicos, v. 16, n. 33, p. 55-80, 2010. https://doi.org/10.1590/S0104-71832010000100005

NOGUEIRA, João. Fortaleza velha: crônicas. 2. Ed. Fortaleza: Ed. UFC / Prefeitura Municipal de Fortaleza, 1981.

OLIVEIRA, C. S. Cidade (in)salubre: ideias e práticas médicas em Fortaleza (1838-1853). Dissertação (Mestrado em História Social). Fortaleza: UFC. 2007.

PREITECELLE, E. A evolução da segregação social e das desigualdades urbanas: o caso da metrópole parisiense nas última décadas. Caderno CRH: Revista Centro de Recursos Humanos da UFBA (Universidade Federal da Bahia), Salvador, n. 36, 2003, p. 27-48.

ROSENDHAL, Zeny. Tempo e temporalidade, espaço e espacialidade: a temporalização do espaço sagrado. Espaço e Cultura, UERJ, RJ, n. 35, p. 09-25, jan./jun. 2014.

https://doi.org/10.12957/espacoecultura.2014.18902

SANTOS, Milton. Espaço e Método. São Paulo, Nobel, 1985.

SILVA, G. A. da. Necroespacialidades: um estudo sobre os espaços socialmente construídos nos cemitérios de São João Batista e Parque da Paz em Fortaleza-Ce. Trabalho de Conclusão de Curso (Graduação em Geografia) - Fortaleza: UECE (Universidade Estadual do Ceará). 2015.

Recebido em: 28/05/2020

Aceito para publicação em: 24/08/2020 